Página inicial: 472 - Página Final: 496

Tipo de artículo: Investigación

\title{
Propuesta del modelo espacial para la evaluación y gestión del territorio, para la incorporación de las Unidades de Planificación y Gestión Territorial (UPGT) al pos-conflicto colombiano
}

\author{
Proposal of Space Model for Land Assessment and Management for the Incorporation \\ of Units of Territorial Planning and Management (UPGT) to the Colombian Post-Conflict
}

Recibido: abril de 2017 Revisado: mayo de $2017 \quad$ Aceptado:junio de 2017

1 Arquitecto de la Universidad de América, Especialista en

Planificación y Administración del

Desarrollo Regional y Magister en el

Manejo Integral de Cuencas

Hidrográficas. Investigador y

docente de la Universidad de

América, Facultad de Arquitectura.

Miembro fundador del grupo

Territorio y Habitabilidad. Bogotá

(Colombia). Contacto:

evrplanifterritorial@gmail.com ;

ernesto.villegas@profesores.uameri

ca.edu.co ORCID:

http://orcid.org/0000-0003-3101-

0351

2 Abogada Ambientalista,

Especialista en Cooperación Internacional para el Desarrollo,

Magister en Estudios Políticos.

Docente de planta de la Facultad de

Medio Ambiente y Recursos

Naturales, de la Universidad

Distrital Francisco Jose de Caldas,

Bogota, Colombia. Miembro del grupo de investigación en Estudios

Ambientales GEA, del programa de Administración Ambiental.

Contacto:aydiazl@udistrital.edu.co ; yolandadiaz80@gmail.com ORCID: http://orcid.org/00000001-5106-5101

3 Abogada, Universidad Colegio Mayor de Nuestra Señora del Rosario; especialista en Derecho Laboral y de la Seguridad Social y en Derecho Administrativo; magíster en Derecho Administrativo de la Universidad del Rosario. Docente y coordinadora académica Universidad El Bosque. Bogotá (Colombia). Contacto: lorenanietov@gmail.com ORCID: http://orcid.org/00000002-6969-6590
Por: Ernesto Villegas Rodríguez ${ }^{1}$, Aura Yolanda Díaz Lozano ${ }^{2}$ \& Lorena Nieto Vargas ${ }^{3}$

\section{Resumen}

Para aportar en la construcción de una paz duradera se necesita darle continuidad a los procesos gubernamentales representados por los propios actores que han de conformar los nuevos territorios y democráticamente establecer desde el gobierno nacional las reglas claras en la ocupación de los mismos. Es así que, se proyectan posibles actuaciones como escenarios desde la incorporación de los entre otros, lo que supone un reto en la articulación urbano - rural que se realiza a través de las Unidades de Planificación y Gestión Territorial (UPGT)

Palabras clave. Posconflicto; Fortalecimiento Institucional; Instrumentos y Herramientas para la Planificación y Gestión Territorial; Contextos Rurales y Urbanos; Gobernabilidad y Gobernanza.

\begin{abstract}
In order to contribute to the construction of a lasting peace, it is necessary to give continuity to governmental processes represented by the real players themselves, who have to constitute the new territories, and democratically, from the national government, to establish clear rules in their occupation. So that possible actions as scenarios are projected as the result of the incorporation of Instruments and Tools for Land Planning and Management, among others, which becomes a challenge in the urban-rural articulation, which takes place through the Units of Planning and Territorial Management (UPGT)
\end{abstract}

Key words: Post-conflict; Institutional Strengthening; Instruments and Tools for Land Planning and Management; Rural and Urban Contexts; Governability; Governance. 


\section{Introducción}

Colombia desde más de cinco décadas ha estado inmersa en un conflicto interno entre dos actores Guerrilla y Estado; lo cual, ha derivado en periodos de violencia continúa incorporándose otros actores como el paramilitarismo en asocio con sectores productivos y en asocio con el Estado en su conformación y mantenimiento, interrelacionándose factores como el narcotráfico. Lo insólito en los respectivos periodos, es la formulación y aprobación de distintos Planes de Desarrollo en contextos geográficos variados como el Nacional (PDN), Departamental (PDD), y Municipal (PDM), también recientemente la puesta en marcha de los Planes de Ordenamiento Territorial de iniciativa Municipalista conocidos como los POTs, a través de la Ley 388 de 1997; además, paralelamente se han desarrollado los Planes de Manejo de Cuencas Hidrográficas conocidos con el nombre de POMCAS, basados a través de los Decretos 1729 de 2002 y 1640 de 2012 elevados a Iinstrumentos para la Planificación, Oordenación ambiental del territorio desde un nivel regional en coordinación con las Corporaciones Autónomas Regionales CARs. Véase Grafica No 1. Jerarquía de los instrumentos y herramienta de gestión y planificación. En el contexto nacional, sobresalen los Planes Esquema de Ordenamiento Territorial (PEOT), que son determinados por el número de concentración poblacional en el nivel local. Véase Figura No 1. Espacialización Territorial de la Incidencia de la Ley 388 de 1997

Grafica No 1. Jerarquía de los instrumentos y herramienta de gestión y planificación.

\section{Pirámide Kelsen Jerarquización de los Instrumentos y Herramientas de Gestión Territorial.}

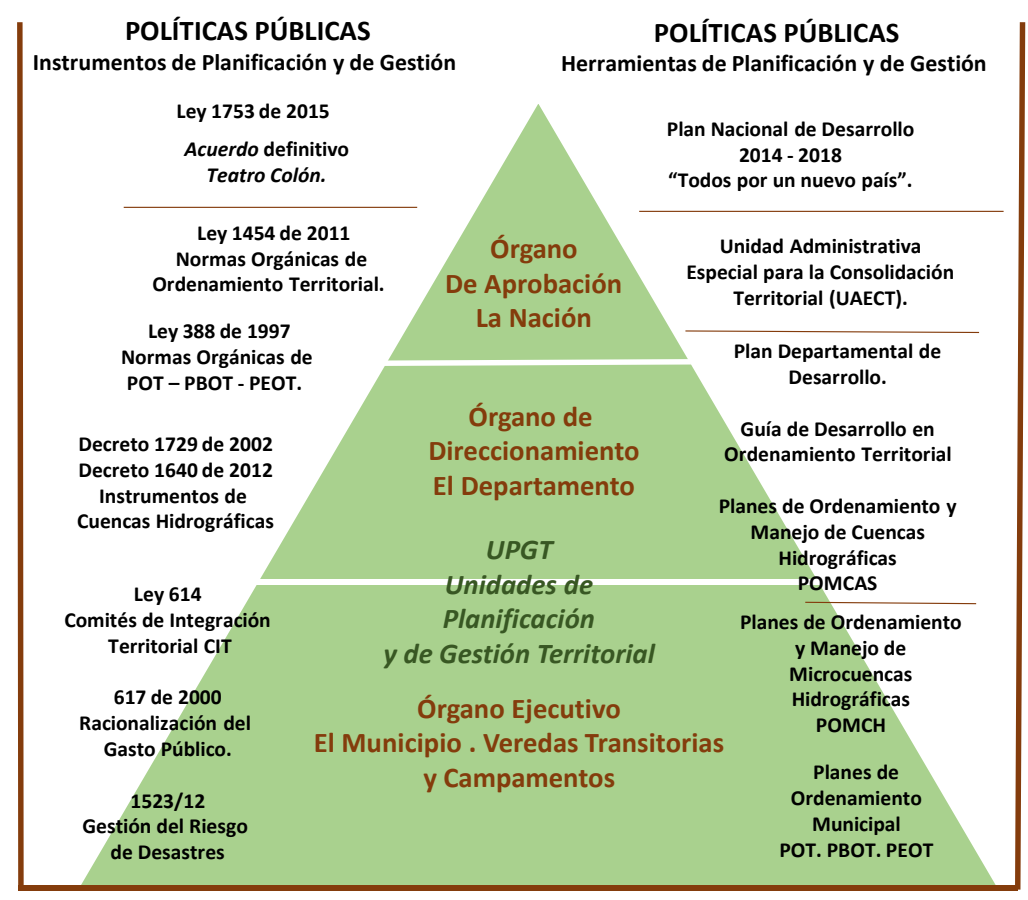

Fuente: Elaboración Arq. Ernesto Villegas Rodríguez. 
Figura No 1. Espacialización Territorial de la Incidencia de la Ley 388 de 1997

\section{Planes de Ordenamiento Territorial en Colombia}

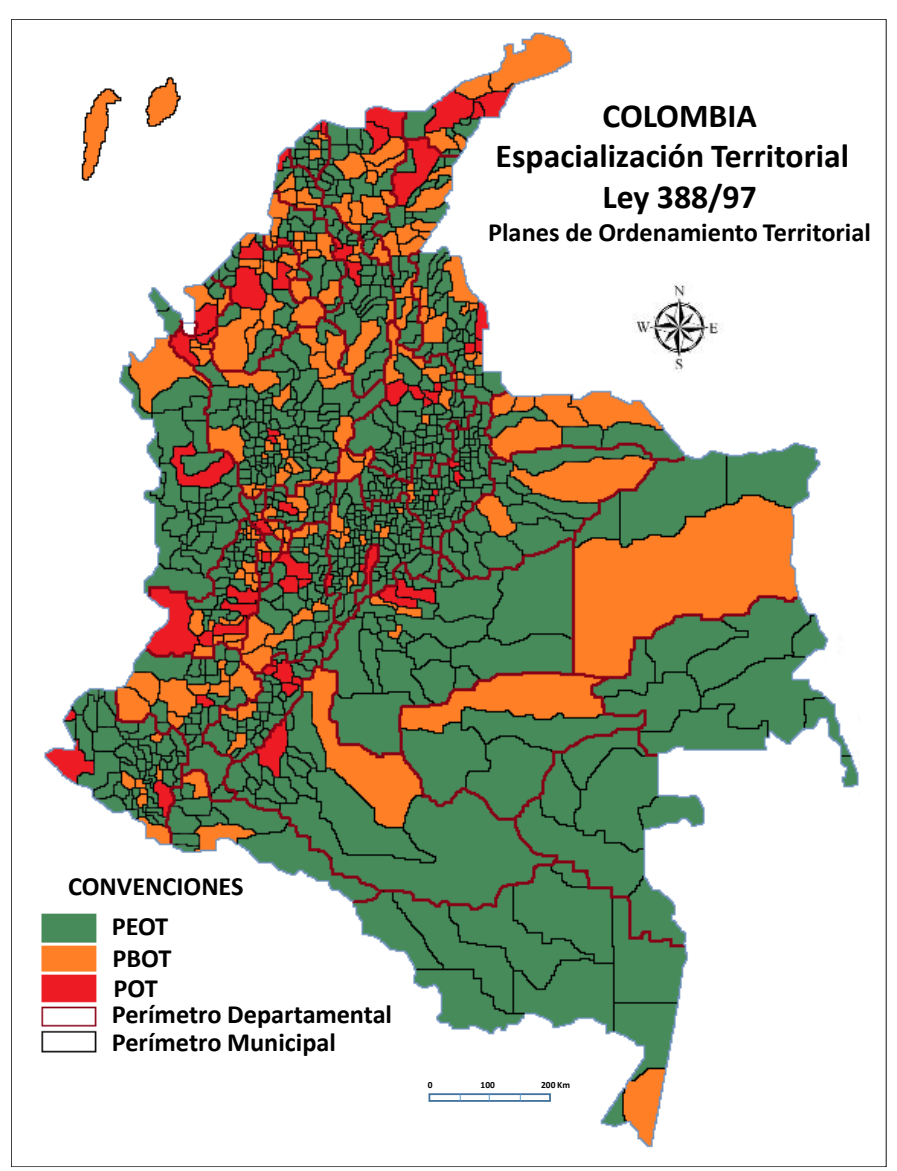

\section{Análisis}

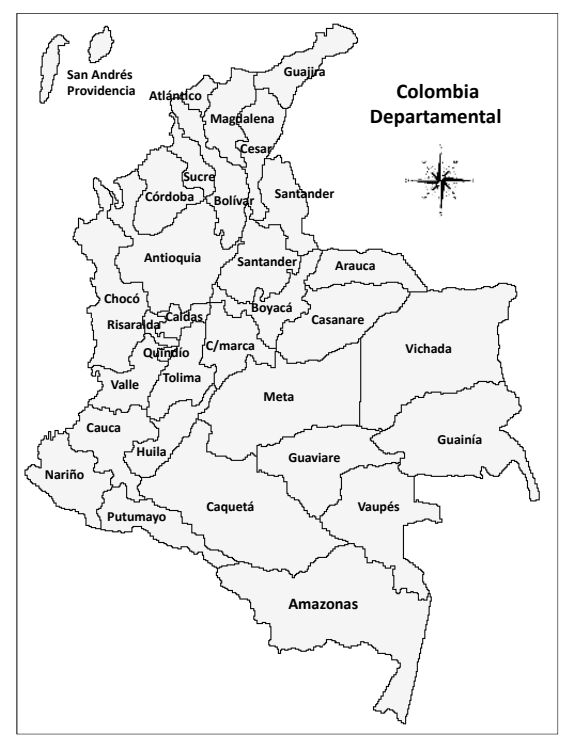

Nótese en color verde, la territorialización de los Planes de Ordenamiento Territorial desde un énfasis de "Esquema", los cuales se busca los siguientes beneficios: Fortalecimiento de la capacidad técnica para implementar procesos de planificación de lo cual se derivan beneficios relacionados con una mayor capacidad de gestión y control del desarrollo territorial. Ley 388 de 1997.

Fuente: Elaboración Propia Arq. Ernesto Villegas Rodríguez.

Lo anterior, con lleva al conocimiento de dos instrumentos de políticas públicas en términos de establecer los enlaces o sinergias de los procesos de planificación y ordenamiento territorial. El Plan de Desarrollo (PD), Plan de Ordenamiento Territorial (POTs) y aparecería un tercero los Planes de Manejo de Ordenación de Cuencas Hidrográficas (POMCAS).

En el año 2000 se promulgó la ley 614 incentivando la creación de Comités de Integración Territorial (CIT), para la adopción de los Planes de Ordenamiento Territorial, cuyo objeto de la ley es la de establecer mecanismos de Integración, Coordinación y Armonización de las diferentes entidades competentes en materia de ordenamiento del territorio, para la implementación de los Planes de Ordenamiento Territorial, sin verse hasta el momento su implementación por medio de las respectivas entidades territoriales municipales.

En el periodo Administración Nacional 2010-2014, A traves del Plan Nacional de Desarrollo y teniendo en cuenta el proceso del de paz a causa del conflicto armado entre Guerrilla y Estado, se estableció el instrumento de gestión institucional conocido como la Unidad Administrativa 
Especial para la Consolidación Territorial (UAECT), determinándose los objetivos, estructura y funciones, su promulgación es respaldado por la Ley 1450 de 2011 Plan Nacional de Desarrollo conocido con el eslogan "Prosperidad para todos" en su artículo 195 que, indica "el direccionamiento estratégico de la Política Nacional de Consolidación Territorial será responsabilidad del Consejo de Seguridad Nacional" 'posteriormente se respalda dicha UAECT, por el Decreto 4161, del 3 de noviembre de 2011.

Las UAECT, por lo tanto, tiene como objetivo principal la implementación, ejecución, y hacer el seguimiento a la Política Nacional de Consolidación Territorial; canalizando, coordinando y articulando la intervención institucional diferenciada en los distintos departamentos de consolidación. Dichas formulaciones a través de las políticas públicas llevaran a la declaratoria en términos territoriales en la espacialización de las distintas actuaciones del estado colombiano en todo el territorio nacional.

Si no se lograse la armonización de los instrumentos a partir de las leyes identificadas se llegaría muy rápidamente a la fragmentación entre el sector rural y urbano a traves de las distintas capitales de departamento de grandes ciudades; que tienen su propia visión del conflicto aisladas de la problemática y un sector rural liderado por sus cabeceras poblacionales muchas de ellas que han sufrido directamente el deterioro ambiental, social y económico por causa del conflicto armado y del aislamiento de inversiones en programas y proyectos del Estado. Aunque son los que han vivido la violencia en plenitud en sus territorios, la herramienta de planificación y gestión territorial conocido como el Plan Desarrollo Nacional (PDN) no ha podido resolver la inequidad más aún los territorios se fragmentaron entre municipios de cuarta, quinta y sexta categoría por la misma ley 617 de 2000.

La realidad en el reconocimiento del conflicto ha sido muy distante como algo aislado a las políticas sociales y económicas; lo cual, ha llevado a proceso territoriales de inequidad y desigualdad extrema con crecimiento y desarrollos insostenibles que están representados en los respectivos contextos de la geografía nacional en los 32 departamentos y en los 1103 municipios reordenados en la ley por población e inversión resaltándose en el territorio el 89\% de los municipios en categorías sexta según la Ley 617 de 2000 (Ley Orgánica de Presupuesto). Véase figura Espacialización categorización municipal por régimen de la ley 617 de 2000. Establece por ingresos y población. Lo cual, es determinante para establecer los niveles de gestión e inversión en infraestructura física que resuelva las necesidades propias de la población, muchas de ellas aisladas del contexto de inversión nacional, problemática que se ha venido acrecentando a lo largo de las décadas alimentado paralelamente por el mismo conflicto armando, clientelismo y la propia corrupción. Solo hasta el proceso administrativo 2010 - 2014 y 2014 - 2018 se sentaron las bases para resolver definitivamente el conflicto, proceso gestionado fuera del territorio colombiano específicamente en la ciudad de la Habana Cuba.

A continuación, se presenta el nivel de actuación de los municipios por Categorías Habitantes entre ingresos corrientes de libre destinación ICLD (SMMLV): Véase figura espacialización categorización municipal por régimen de la Ley 617 de 2000. Y la Tabla No 1., de Cuantificación de la Categorización municipal.

Especial $>500.001>400.000$

1. $\quad 500.000100 .001100 .000400 .000$

2. $\quad 100.00050 .00150 .000100 .000$

3. $\quad 50.00030 .00130 .00050 .000$ 
4. $\quad 30.00020 .00125 .00030 .000$

5. 20.00010 .00115 .00025 .000

6. $<10.000<15.000$

la categoría 6 agrupa a los municipios con menor volumen de ICLD y/o menos habitantes; en Colombia el 89\% de los municipios está clasificado dentro de la categoría 6 para el año 2007; para un total de 984 municipios.

Tabla No 1. Cuantificación de la Categorización municipal.

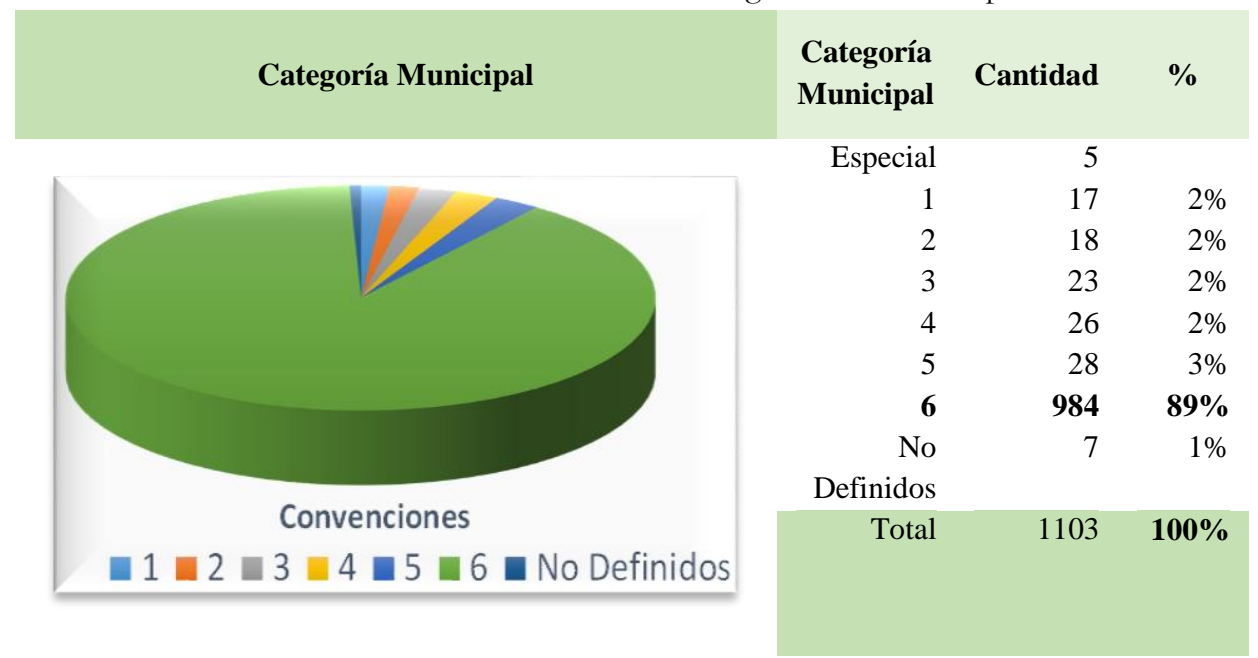

Fuente: Elaboración Arq. Ernesto Villegas Rodriguez.

Lo anterior, si al comparar la figura No 1. Espacialización Territorial de la Incidencia de la Ley 388 de 1997, y la Figura No 2. Espacialización categorización municipal por régimen de la ley 617 de 2000, es fundamental la asociación entre Planes Esquema de Ordenamiento Territorial y la capacidad de gestión y presupuestal de los municipios, que al final debe reflejar la gran complejidad de la planificación y disparidades territoriales que no se han resulto por lo bajos ingresos de los municipios y los altos problemas ambientales que se reflejan tanto en sus áreas urbanas como rurales.

Datos de recaudo tributario con lo que se puede medir la capacidad institucional entre los periodos 1970 y 2015 estudio citado (López, C. 2016) Colombia pasó de un recaudo tributario del 8\% del PIB a uno del 14\% del PIB, por debajo de países como Brasil que llegaron al 35\%. Esto es determinante en la prestación de servicios sociales básicos, lo cual ha identificado al estado dentro del asistencialismo. El punto central del proceso de paz es lograr tener territorios institucionalizados como estrategia de la política pública dentro de la transición de ese poder complejo y efectivo ejercido por ciertos actores en el territorio. La construcción de Estado a nivel local se identifica a lo largo de las mismas Constitución Política de 1991 y de las mismas leyes como es la 1454 (LOOT), que fortalece un gran número de asociatividades territoriales con el fin de fortalecer la descentralización administrativa y territorial, creando municipios y departamentos fuertes en un proceso que resulta de pasar de un extremo a otro que resulta de combinar esfuerzos e iniciativas y nuevos poderes institucionales como sociales y económicos. 
Igualmente, desde la misma promulgación de la Ley Orgánica de Ordenamiento Territorial (1454 de 2011), se complementa con la Ley de Ordenamiento Territorial y Desarrollo Sostenible No 18308 del 18 de junio de 2008 (LOTDS) en su artículo $3^{\circ}$ establece que el ordenamiento territorial tiene como objetivo el mejoramiento de la calidad de vida de la población, la integración social en el territorio y el uso sustentable de los recursos naturales y culturales. De modo que, se trata de formular un modelo territorial departamental y/o local, considerando sus potencialidades y corrigiendo sus disfuncionalidades. Lo cual, se espera que se tenga una nueva visión administrativa del territorio nacional. Véase la figura No 2 Espacialización categorización municipal por régimen de la ley 617 de 2000. Que de alguna manera muestra la importancia de fortalecer las entidades locales con departamentos viables.

Figura No 2. Espacialización categorización municipal por régimen de la ley 617 de 2000

División Municipal

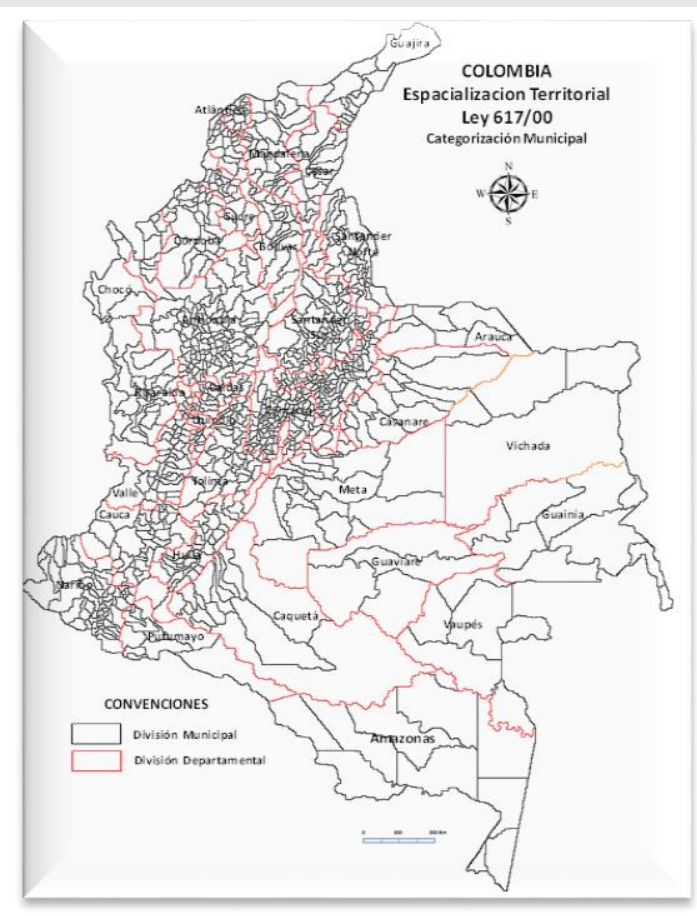

\section{Espacialización Municipal}

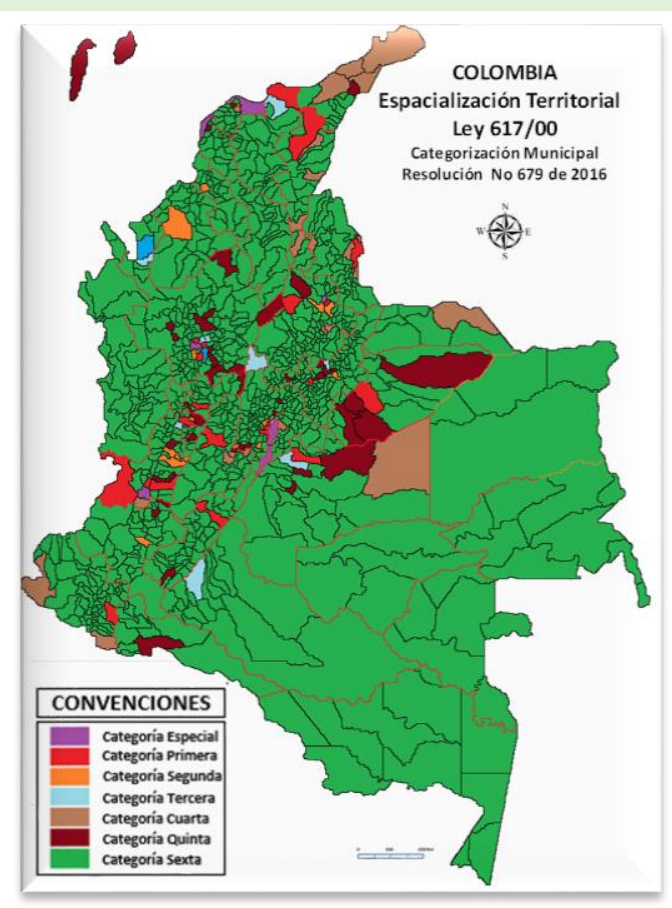

Fuente: Elaboración Arq. Ernesto Villegas Rodríguez

Finalmente, el artículo se apoyará de la información publicada directamente por el gobierno Nacional como de referentes de autores expertos en el manejo de conflictos territoriales. Como de la misma posición de las autoras en la puesta en escena de los instrumentos y herramientas de planificación y de gestión territorial, planteadas para la organización del modelo espacial que garantice la articulación de los distintos programas y proyectos de inversión en lo ambiental, social y económico a traves de los planes departamentales y municipales y las nuevas instancias de participación ciudadana y política enmarcadas en el nuevo horizonte real de país y organizadas bajo la propuesta que ponemos en conocimiento en la puesta en escena en la incorporación de las UPGT al posconflicto colombiano. 


\section{Materiales y Métodos}

\section{Área de Estudio}

La investigación se desarrolla en el contexto Veredal como instancia articuladora del territorio municipal, inmersos en quince (15), departamentos del contexto de la nación donde se identificaron ocho (8) campamentos y veinte tres (23) Zonas Veredales como disposición de los diálogos del Gobierno Nacional (Habana Cuba), en asocio con las FARC EP, en los diálogos de la Paz, mostradas en la Figura No 3 Espacialización Zonas de Normalización Transitorias. Estas zonas abarcan en términos departamentales el 46\% del territorio nacional distribuidos en los departamentos de: Guajira, Antioquia, Córdoba, Chocó, Norte de Santander, Cesar; Huila, Cauca, Nariño, Putumayo, Caquetá, Meta, Vichada, Guaviare, Guainía y Arauca. Véase la tabla No 2.

Tabla No 2. Distribución de las veredas en las que se dará la concentración están ubicadas en los municipios.

\begin{tabular}{|c|c|c|c|}
\hline Departamento & Municipio & Vereda & $\begin{array}{l}\text { Campamentos } \\
\text { Especiales }\end{array}$ \\
\hline Cesar & $\mathrm{LaPaz}$ & 1 & \\
\hline $\begin{array}{l}\text { Norte de } \\
\text { Santander: }\end{array}$ & Tibú & 1 & \\
\hline Antioquia: & Remedios, Ituango, Dabeiba & 3 & Vigía del Fuerte 1 \\
\hline Tolima: & Planadas, Villarica & 2 & \\
\hline Cauca: & Buenos Aires, Caldono & 2 & Corinto 1 \\
\hline Chocó & Riosucio & & 1 \\
\hline Nariño: & Policarpa, Tumaco & 2 & \\
\hline Putumayo: & Puerto Asís & 1 & \\
\hline Caquetá: & Montañita, Cartagena del Chairá & 2 & San Vicente 1 \\
\hline Arauca: & Arauquita, Tame & 2 & \\
\hline Meta: & Macarena, Mapiripán, Mesetas, Vistahermosa & 4 & Lozada 1 \\
\hline Vichada: & Cumaribo & 1 & \\
\hline Guaviare: & $\begin{array}{l}\text { San José del Guaviare (este), San José del Guaviare } \\
\text { (oeste) }\end{array}$ & 2 & \\
\hline Guainía & Puerto Colombia & & 1 \\
\hline Guajira & Fonseca & & 1 \\
\hline Córdoba & Tierra Alta & & 1 \\
\hline Total & & 23 & 8 \\
\hline
\end{tabular}

Fuente: Elaboración Arq. Ernesto Villegas Rodríguez.

Según la Tabla No 1., cerca del 89\% de los municipios de Colombia se encuentran en sexta categoría, lo que quiere decir que son territorios con poca capacidad fiscal al recibir menos recursos del Estado, haciendo que su dependencia de la nación sea mayor ya que: Poseen menor capacidad de generar ingresos propios y consecuentemente presentan escapes presupuestales para emprender iniciativas propias de política pública e inversión. Esto obliga a seguir pensando y estudiando lo local, como célula fundamental del funcionamiento de Colombia en sus modos de gestión, y galantes del nuevo proceso de vinculación de actores que hoy están denominados como Sociedad Civil y con la potestad y experiencia de jalonar los nuevos procesos de desarrollo y crecimiento económico en territorios municipales de periferia con granes potencialidades ambientales pero aislados por la falta de infraestructura física como de equipamientos sociales. 


\section{Materiales}

Se construyó la base de datos con información secundaria obtenida en las bases de datos del gobierno nacional como el Departamento Nacional de Planeación (DNP), Sistema de Geográfica para la Planeación y el Ordenamiento Territorial (SIGOT), que reúne la información de 16 autoridades e instancias en el Sistema de Planeación del Territorio en el nivel Nacional, Departamental y Local. (IGAC, 2017). La base de datos se organizó y se espacializó en el mapa de Colombia dentro de los contextos: municipal y departamental en lo relacionado con la aplicabilidad de los instrumentos de planificación de la Ley 388 de 1997 y de la Ley 617 de 2000: Además, en términos espaciales la organización de los vínculos desde la dimensión administrativa los enlaces entre centros poblados de capitales que jalonen y verifique el cumplimiento de las políticas públicas, inversiones de capitales nacionales como internacionales, además de la articulación de Planes de Desarrollo desde una nueva visión denominados de Segunda Generación, que amerita cambios de fondo donde la asociatividad y armonización territorial sea la carta de articulación de las UPGT.

\section{Métodos}

El análisis de la información obtenida y mapeada recoge la información para el presente artículo a través del documento de la firma de la Paz, entre el gobierno colombiano y las FARC-EP, especialmente en lo referente al desarrollo rural y las determinaciones de concentración territorial en las Zonas Veredales Transitorias de Normalización. Además de la interpretación de políticas públicas referentes a temas de la planificación y la gestión territorial.

Para ello, se ha consultado gran variabilidad de la información en artículos, libros entre otros, que han representado posturas en el manejo del desarrollo rural agrario, competitividad de la economía a través de ciudades competitivas, algunos planes de desarrollo en sus distintos contextos, planes de ordenamiento territorial ya que su contexto se enmarca en los municipios colombianos especialmente en la categoría sexta con el 89\% del territorio nacional según la Ley 617 de 2000. Y su ejecución especialmente en los Planes Esquemas de Ordenamiento Territorial PEOT.

Otra de las características desde lo físico son las inversiones en infraestructura productiva y reproductiva siendo estas dos la base del desarrollo y crecimiento de los territorios desde la dimensión social y a su vez enmarcada en las características poblaciones por su concentración en centros poblados menores ordenados y manejo en asocio desde variables ambientales ayudando a la interpretación y valoración del paisaje bien sea natural o antrópico. Desde lo espacial; el artículo debe superar el escenario pesimista y debe trascender al escenario optimista propositivo para establecer la dimensión territorial desde lo urbano funcional y urbano regional.

De la misma manera, se recogerá la información construida desde la Matriz ESPACIAL como herramienta para identificar las debilidades, las oportunidades, fortalezas y amenazas del escenario optimista propositivo. El análisis de dicha matriz será complementado con la Matriz Vester, donde se identificaron cada una de las dimensiones del desarrollo el nivel de criticidad para construir las estrategias y mecanismos enfocados a los factores más determinantes de las distintas políticas públicas promulgadas en desarrollo del posconflicto especialmente articuladas al fortalecimiento de la gobernabilidad y gobernanza institucional y territorial. Véase planteamientos de la investigación, La 
descentralización fiscal y el desarrollo municipal como herramienta en la planificación y armonización territorial Villegas y García Universidad de América, 2017.

Por lo tanto, la investigación a través del "proyecto de investigación" ("Las UPGT una responsabilidad gubernamental en la articulación de políticas de GIRH”); establece niveles de actuación para la incorporación de las denominadas políticas públicas que a lo largo del tiempo se han promulgado sin evaluarse su verdadero impacto a la realidad territorial. En ello, el resultado de este artículo, se presenta y se abordará el reconocimiento en la aplicabilidad de las denominadas "Unidades de Planificación y Gestión Territorial (UPGT); (Véase el libro Contexto de la planificación territorial, hacia la aplicación de instrumentos de gestión urbano rural (Ernesto Villegas Rodríguez 2015)).

Como modelo de articulación territorial donde la espacialidad contemplará los alcances de las distintas instituciones que participan en la consolidación del desarrollo y el crecimiento social y económico en armonía con la política ambiental, lo que equivale a una mayor visión de futuro sostenible en términos de la gobernabilidad y fortalecimiento de la gobernanza del agua y territorial, el enfoque de desarrollo municipal promoverá la búsqueda de pactos integrales y de alianzas estrategias entre voluntades locales, departamentales y regionales si fuese el caso, como actores implicados en las tomas de decisiones de forma colectiva teniendo en cuenta procesos de asociatividad territorial. Véase Ley Orgánica de Ordenamiento Territorial 1454 de 2011.

Las condiciones reales de la planificación y gestión estatal en las tomas de decisiones, las cuales representan una visión integral del "COMO" se puede plantear la articulación de las decisiones recientes del gobierno nacional en el proceso de negociación por más de cinco años 2010 a octubre de 2016 de la Habana Cuba, culminándose en la firma de la PAZ llevado a la convalidación por parte del elector primario en un Plebiscito en octubre 02 de 2016 dándose la sorpresa en la pegunta del SI o NO ganando este último aunque no en un margen amplio complejizando mucho más el distanciamiento entre los que viven en la ciudad y los otros que viven en el sector rural.

La interpretación de dichos resultados es real a los verdaderos problemas de la nación que han llevado al reconocimiento que existe un sector urbano determinado por el proceso de clases sociales que no han entendido que la otra Colombia es la que ha estado en guerra y que dichas actividades desarrolladas en dichos contextos han sido determinantes para el abastecimiento de los centros urbanos demandantes de servicios productivos como ambientales. En ello la consolidación de áreas marginales de periferia relacionadas con el desplazamiento forzado del campo a la ciudad con lo cual se han construido planes de desarrollo por fuera de la realidad del 89\% del territorio nacional conocidos a través de las entidades municipales con vocaciones rural y categorizados por la Ley 617 de 2000 en categoría Sexta (ICLD), donde procesos de planificación y de ordenamiento territorial se han enfocado en los centro poblados con problemas complejos vistos desde un enfoque netamente urbanístico.

Bajo estos resultados el artículo propone desde la aplicabilidad de un gran número de Instrumentos y sus respectivas Herramientas de Planificación y Gestión Territorial, su propia caracterización a soluciones desde la propuesta del modelo espacial territorial, contextualizados en los niveles político administrativos actuales, las decisiones de políticas públicas, algunas de ellas enmarcadas dentro de los compromisos del mismo proceso de paz y otras que a lo largo de las mismas políticas públicas vienen incidiendo de forma directa en la puesta de nuevos modelos territoriales, que administrativamente 
exigen cambios inmediatos del "COMO, DONDE y CONQUIEN" se lleven a cabo la puesta en marcha del modelo político administrativo en la articulación de programas y proyectos donde se evalúe las interrelaciones de las Dimensiones del Desarrollo entendiéndose la ambiental, social, económica, cultural, administrativa y territorial que coadyuven en el mejoramiento de los territorios y por ende al fortalecimiento de la institucionalidad hacia una gobernabilidad estable, progresista y duradera representada en una gobernanza con equidad y representativa en una democracia plena a lo largo de los departamentos, municipios y ciudades que dentro su desarrollo y concentración poblacional son determinantes en la inversión pública a sus características propias del ordenamiento territorial.

Es amplio los referentes bibliográficos de autores y expertos en la solución de conflictos consultados, como de las experiencias en la solución definitiva de conflictos armados en países europeos, africanos como en el nivel latinoamericano. (Véase Desarrollo economía local y paz territorial, "Experiencias y reflexiones en contextos de posconflicto, Una iniciativa apoyada por la Unión Europea y el Gobierno colombiano). Las Políticas públicas las cuales las conocemos dentro de la planificación y gestión territorial como los instrumentos y las acciones que se desprenden de ellas denominadas como herramientas de planificación ejecutadas a través de los planes de desarrollo y de ordenamiento territorial, son determinantes en la visión de la segunda generación de planes puesta de dichos instrumentos y herramientas de planificación y de gestión que cambiarían el sentido de la política y su qué hacer inmediato en la articulación de programas y proyectos a los territorios de forma coherente desde las bases ambientales, sociales y económicas articulas a las administraciones públicas locales y departamentales que se integren de forma espacial y llevando a los planteamientos de asociatividad territorial de una nueva regionalización con carácter político administrativo como se muestra en la propuesta del Modelo espacial de evaluación y gestión del territorio para la incorporación de las UPGT al post-conflicto colombiano.

\section{Marco de Referencia}

\section{Antecedentes una posición para el desarrollo del Modelo}

El conflicto colombiano por su carácter multidisciplinar en los territorios, ha determinado por su propias dinámicas ambientales, sociales y económicas la identificación de distintas características de institucionalidad en la puesta en marcha de las políticas públicas promulgadas desde el centro del país y que finalmente desde lo ambiental repercuten en los territorios municipales, que al no ser avalados o reconocidos por sus propios Planes de Ordenamiento Territorial, conllevan, a los cambios de vocación del uso del suelo en términos productivos, teniendo en cuenta, que muchos de los municipios están determinados por su vocación ambiental y su categoría del uno al seis en su régimen administrativo siendo este último régimen de sexta, como resultado en 990 entidades municipales para un $89 \%$ del total de los municipios colombianos.

Algunos indicadores de desarrollo y crecimiento que están directamente relacionados en el aumento de la población es la inversión en salud y educación que son parámetros para entender las condiciones en las que se vive y que de alguna manera se enmarcan en las grandes disparidades territoriales; uno de ellos son los ingresos monetarios y el análisis multidimensional a la accesibilidad a los servicios básicos establecida como metodología del Departamento Nacional de Estadística DANE para medir el nivel de desarrollo de la población. Colombia calcula la pobreza a partir de los ingresos monetarios de los hogares, pero también a través del Índice de Pobreza Multidimensional (IPM), que evalúa cinco 
dimensiones de los hogares colombianos: condiciones educativas del hogar; de la niñez y la juventud; trabajo; salud, y acceso a servicios públicos y condiciones de la vivienda. (Retomado por el DANE)

La característica espacial en la identificación en la propuesta del modelo espacial de evaluación y gestión del territorio para la incorporación de las UPGT al post-conflicto colombiano. Es determinante las acciones llevadas por el estado; pero que para los resultados de inversión sigue siendo para el DANE; la diferencia entre el campo y las ciudades más aun para los de régimen municipal de sexta categoría como zonas rurales donde la pobreza cobija al $40 \%$ de la población; Y según la CEPAL, será fundamental enfocar los esfuerzos en mantener el empleo, para que la población más pobre que logró subir un escalón se sostenga en ese nivel. Característica determinante en municipios y veredas localizadas en la verificación del proceso de paz entre FARC y Gobierno nacional. Más aún en territorio enfrentado al desarrollo de proyectos y programas de post-conflicto donde los elevados índices de pobreza, la inestabilidad de las actividades económicas evidencia la falta de intervenciones territoriales del Estado colombiano por medio de la ejecución de los Planes de Desarrollo (PD), en dos niveles específicos el departamental y el municipal.

Como tema central del artículo, puede ser objeto de miles de interpretación en términos de actuación y participación de recursos tanto de los dos sectores públicos y privado, que repercute directamente en la misma sociedad civil, la cual, está en condiciones de vulnerabilidad por la misma actuación de los dos anteriores. Por lo tanto, los regímenes laborales tanto para las ciudades y el campo con grandes disparidades aumentando la brecha de desarrollo y crecimiento de la ciudad y el campo. Sin lograrse establecer proyectos articulados directamente a programas sociales y económicos que identifiquen los valores escénicos productivos de los que producen y consumen, desde las mismas herramientas de planificación (PD), que por más de cuarenta y siete años (47), han llevado en sus estrategias y pilares los términos de equidad, inversión social y desarrollo económico por lo menos en catorce Planes de Desarrollo Nacional desde 1969 hasta 2018.

Lo anterior se evidencia en términos de desarrollo social con equidad y crecimiento económico con sostenibilidad, la gran debilidad político-administrativo que directamente ha venido debilitando las distintas instancias institucionales en cada una de las entidades territoriales que han proclamado bajo sus propios intereses los procesos de descentralización administrativa. No se puede promover un desarrollo territorial sin herramientas de planificación y de gestión verdaderas de carácter gubernamental que satisfagan las necesidades territoriales con esquemas que en el tiempo que logren disminuir la pobreza entre las brechas de la ciudad y el campo.

Lo anterior, exige de inmediato una nueva arquitectura institucional y de un marco legal normativo específico que legitime la construcción del nuevo territorio, que promueva un desarrollo con equidad territorial con crecimiento económico sostenible social y ambientalmente. Este tipo de reflexión, se debe hacer a partir de los 32 departamentos que deben identificar y fortalecer a partir de la creación de regiones administrativas de planificación en compañía de las provincias las entidades municipales que sobrepasan los mil noventa y ocho municipios contextualizados por la actual legislación (Ley 617 de 2000). Y asociados territorialmente en cumplimiento de los mismos decretos leyes que propician para el post-conflicto las nuevas relaciones territoriales para enfrentar las inversiones sociales que garanticen la denominada paz duradera. 
Para ello, el Modelo espacial de evaluación y gestión del territorio para la incorporación de las UPGT al post-conflicto colombiano; contribuye en lo propositivo en los actos cumplidos y refrendados en el proceso de PAZ entre la guerrilla FARC-EP y posteriormente con el Ejército de Liberación Nacional. Lo anterior identifica que no es solamente la dejación de armas e inserción de los excombatientes a la vida civil, sino reformas políticas que garanticen verdaderos Planes de Desarrollo, que conlleven, al fortalecimiento de la institucional territorial que enmarque una mayor gobernabilidad y una gobernanza con fortalecimiento de una sociedad más participativa y proactiva en la construcción de un nuevo modelo de territorio incluyente políticamente, que evidencien los cambios en la ejecución de programas y proyectos funcionales construidos participativamente con seguimiento y evaluados en conjunto técnicamente. Véase Grafica No 2. Estructura administrativa para el Posconflicto propuesta en este artículo.

Lo que llevará a acuerdos generales sobre las estrategias territoriales la recuperación de la credibilidad y legitimidad de las instituciones desde lo local mediante la construcción y administración conjunta, en la implementación de Planes de Desarrollo y Planes de Ordenamiento Territorial modernos ejecutados o denominados para tiempos complejos de Segunda Generación (SG). La verdadera voluntad política y vinculantes a Planes de Desarrollo Departamentales y Municipales que no han podido evidenciar desde los últimos cincuenta años los deseos sociales de las poblaciones rurales y urbanas en la solución de sus problemas sociales y económicos que directamente se relacionan con su ocupación territorial y su incidencia con los recursos naturales o también recursos humanos.

La puesta en marcha de una de las primeras etapas del proceso de paz firmado en septiembre de 2016 entre FARC-EP y el Gobierno Nacional, es legitimar a la Vereda Municipal como el escenario para el desarrollo participativo en la ejecución de las políticas transitorias que identificaran la importancia en la construcción de proceso de desarrollo productivo rural, determinado a lo largo del territorio nacional; la ubicación de las denominadas Zonas Veredales Transitorias de Normalización (ZVTN), para la concentración de la guerrilla para el Postconflicto. Lo cual, conlleva al reconocimiento de la participación de los distintos actores que respalden las distintas etapas de la incorporación a la vida civil de las personas que a su vez serán protagonistas de la política territorial y permanente. Véase figura 3 Espacialización de zonas de normalización transitorias.

Lo anterior evidencia, en el momento que el proceso se consolide territorialmente en la permanencia de los que ayer estuvieron en armas y hoy por resultados del proceso de paz; serán los promotores de paz reconocidos por el mismo gobierno. Ellos han de consolidarse en partidos políticos, en hacer política de forma pacífica en los territorios donde han tenido injerencia a lo largo de las cinco décadas de conflicto. Los cuatro espacios territoriales conformados por los quince (16) departamentos y las veintitrés (23) veredas pertenecientes a entidades locales de periferia se denominarán las regiones de la PAZ. (Veamos la Tabla No 3 Estructura Departamental para la conformación de las Regiones de la PAZ; y la figura No 3 Espacialización Zonas Veredales Transitorias de Normalización. 
Tabla No 3. Estructura Departamental para la conformación de las Regiones de la PAZ

Región

1. UPGT

Pacífico Occidente

2. UPGT

Oriente

3. UPGT

Caribe Sur

4. UPGT

Pacífico Centro

\section{Departamentos}

Chocó, Antioquia y Córdoba.

Arauca, meta, Putumayo, Caquetá, Vichada, Gaviare,

Guainía.

Guajira, Cesar y Santander.

Nariño, cauca y Tolima.
Total

3

7

3

3

Fuente: Elaboración Arq. Ernesto Villegas Rodríguez,

Figura No 3. Espacialización Zonas Veredales Transitorias de Normalización

\section{Zonas Veredales Transitorias de Normalización}

(ZVTN)

Análisis

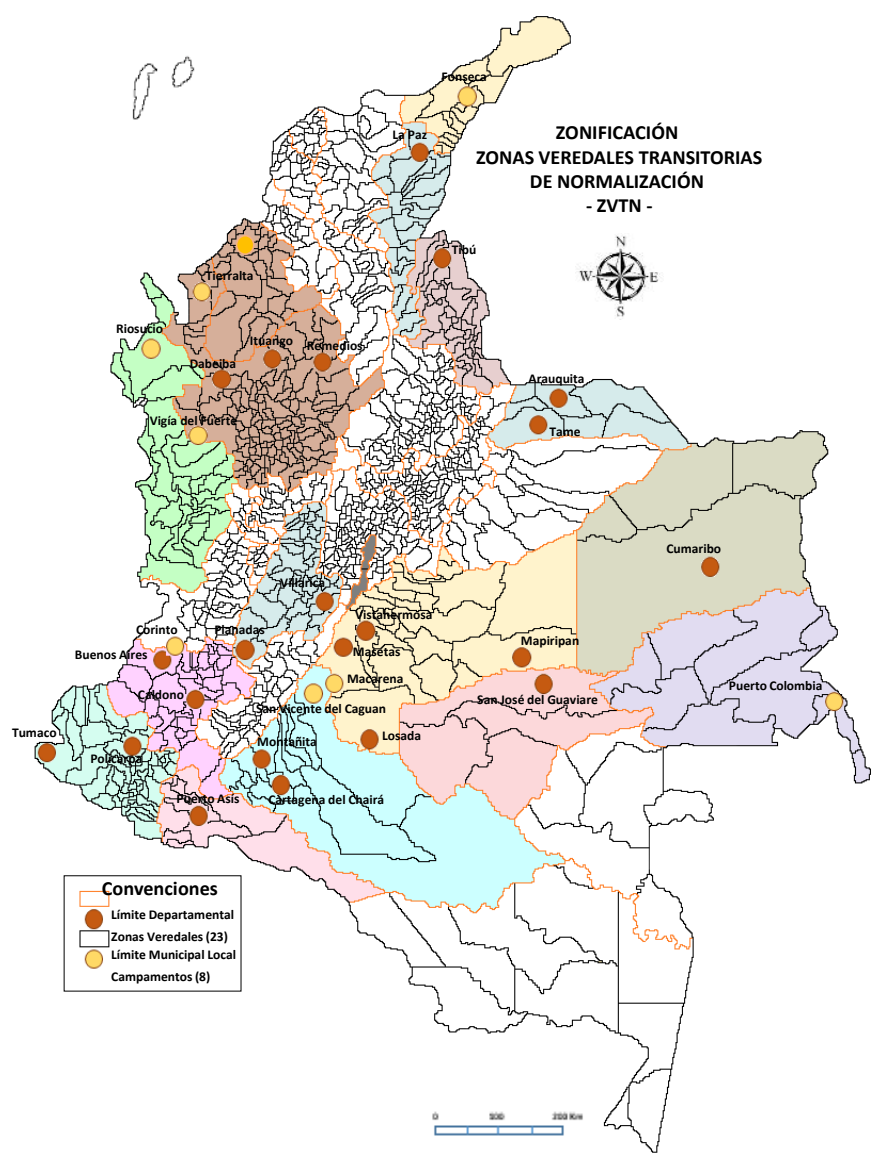

Las características municipales $m$ de los 1103 municipios que tiene el país, las guerrillas han operado en 281, es decir el $\mathbf{2 4 \%}$. En dicho grupo de municipios vive algo más del $16 \%$ de la población.

De estos 281 municipios en 190 hay presencia de economías ilegales ya sea cultivos de hoja de coca, minería criminal o contrabando de gran escala.

En 160 de estos municipios existe presencia de otros grupos armados ilegales o actores criminales.

Fuente: Elaboración Arq. Ernesto Villegas Rodríguez, Tomado de la información de Ariel Avila 27/06/2016 http://caracol.com.co/radio/2016/06/27/nacional/1467049362 410253.html 


\section{Perspectivas territoriales desde los Planes de Desarrollo como modelo institucional}

Se tomará algunas características de los distintos planes de desarrollo, que se han ejecutado a lo largo de los últimos cincuenta años, el análisis de las características, en el marco de lo teórico y conceptual, proporcionará para el articulo y al proyecto de investigación los elementos y las bases para tomar decisiones, teniendo en cuenta el verdadero valor de las políticas desarrolladas cada cuatro años de cada una de las administraciones que han delineado el nivel de desarrollo social y los desequilibrios territoriales entre los departamentos y municipios que serán objeto de análisis a través de los siguientes: Véase tabla No 4 Consolidación Planes de Desarrollo Nacionales 1970 - 2018

Tabla No 4 Consolidación Planes Nacionales de Desarrollo. 1970 - 2018

\begin{tabular}{|c|l|l|l|}
\hline No & \multicolumn{1}{|c|}{ Nombre del Plan de Desarrollo } & \multicolumn{1}{|c|}{ Periodo } & Periodo Administrativo \\
\hline $\mathbf{1}$ & Las cuatro estrategias & $(1970-1974)$ & $\checkmark$ Misael Pastrana. \\
\hline $\mathbf{2}$ & Para cerrar la brecha & $(1974-1978)$ & $\checkmark$ Alfonso López. \\
\hline $\mathbf{3}$ & Plan de integración social & $(1978-1982)$ & $\checkmark$ Julio César Turbay. \\
\hline $\mathbf{4}$ & Cambio con equidad & $(1982-1986)$ & $\checkmark$ Belisario Betancur. \\
\hline $\mathbf{5}$ & Plan de economía social & $(1986-1990)$ & $\checkmark$ Virgilio Barco \\
\hline $\mathbf{6}$ & La revolución pacífica & $(1990-1994)$ & $\checkmark$ César Gaviria. \\
\hline $\mathbf{7}$ & El salto social & $(1994-1998)$ & $\checkmark$ Ernesto Samper. \\
\hline $\mathbf{8}$ & Cambio para construir la paz & $(1998-2002)$ & $\checkmark$ Andrés Pastrana \\
\hline $\mathbf{9}$ & Hacia un Estado Comunitario & $(2002-2006)$ & $\checkmark$ Álvaro Uribe Vélez. \\
\hline $\mathbf{1 0}$ & Estado Comunitario desarrollo para todos & $(2006-2010)$ & $\checkmark$ Álvaro Uribe Vélez. \\
\hline $\mathbf{1 1}$ & Prosperidad para todos & $(2010-2014)$ & $\checkmark$ Juan Manuel Santos. \\
\hline $\mathbf{1 2}$ & $\begin{array}{l}\text { Todos por Un Nuevo País "Paz, Equidad, } \\
\text { educación }\end{array}$ & $(2014-2018)$ & $\checkmark$ Juan Manuel Santos. \\
\hline
\end{tabular}

Fuente: Elaboración Arq. Ernesto Villegas Rodríguez.

Considerado el Plan de Desarrollo como la herramienta formal y legal por medio de la cual, se trazan los objetivos de gobierno, permitiendo la evaluación de su gestión, esta es la herramienta que sirve de base y provee de lineamientos estratégicos de las políticas públicas formuladas, se socialicen, evalúen, se realice el seguimiento. A continuación se muestran por periodos administrativos los pilares de desarrollo y crecimiento que se planificaban a lo largo de todo el territorio nacional y que siguen enunciando sin ser representativos a lo largo del territorio nacional y que deberían ser hoy de una Colombia totalmente distinta que pudiera representarse en país con indicadores altísimos de calidad y oferta de infraestructura social teniendo a Colombia en los más altos estándares de calidad.

Algunas políticas de desarrollo urbano, concentración de los recursos en el desarrollo industrial y la infraestructura, estimular la construcción través del trabajo comunitario, aumento de la productividad agraria, buscando la generación de empleo para lograr mayores niveles de ingresos, además del crecimiento a las importaciones son algunos de los pilares que veremos en los siguientes Planes Nacionales.

- Son algunos de los parámetros impulsados en el periodo 1970-1974. La implantación de la Unidad de Poder Adquisitivo Constante conocido como el UPAC tenía como objetivo 
mantener el poder adquisitivo de la moneda y ofrecer una solución a los colombianos que necesitaban tomar un crédito hipotecario de largo plazo para comprar vivienda según informe del Banco de La Republica. Metodología de cálculo de los valores de la UPAC, (Información disponible desde el 15 de septiembre de 1972 hasta el 31 de diciembre de 1999.

- Algunas orientaciones para reducir las brechas que existen entre el campo y la ciudad, es logrando un crecimiento en la economía, que haga posible la creación masiva de empleo productivo, por lo tanto, que beneficie a la mayoría de la población pobre de la sociedad. Basados directamente en el componente agrario, la industria, el fomento de las exportaciones y el desarrollo rural y regional fueron las fortalezas empleadas en el periodo 1974-1978. Colombia se ha visto afectada a lo largo de este periodo en materia de medio ambiente no fue un programa de tener en cuenta.

- Los temas referentes a los componentes sociales y económicos en cuanto a la salud y educación, fue el objetivo de estos cuatro años - 1978-1982 - el sector económico se localizó en el transporte, comunicaciones y el sector energético minero realizando obras como las de Chivor II, Paipa II, la térmica de Chinú, Zipaquirá IV dando entrada a la explotación de carbón del Cerrejón, de níquel en Cerromatoso y la explotación de yacimientos petroleros.

- De acuerdo al periodo 1982-1986, se caracterizó por la voluntad de la erradicación la violencia objeto del narcotráfico y del conflicto armado. La reactivación económica y consolidación del desarrollo y el ordenamiento social, basándose en el desarrollo de políticas de producción del sector agropecuaria, la industria, la vivienda, la minería, infraestructura y turismo. En el periodo 1986 - 1990, el plan de desarrollo, hacía reticencia a un mejoramiento a la planeación de territorio rural y urbano, buscándose perfeccionar los instrumentos de planificación y de gestión territorial, que conformaban el Sistema Nacional de Planeación.

- El Plan Nacional de Desarrollo - 1990-1994 - pretendía mejorar la infraestructura construyéndose más de 8.000 kilómetros, la adecuación de más de 500.000 hectáreas para elevar la productividad agrícola; la inversión en investigación científica para logar un equilibrio entre la apertura económica y la modernización de manera que se lograra procesos productivos más sostenibles; a la vez, se buscó el cubrimiento total de salud y educación primaria en el sector rural. Se observa que parte de los procesos planteados desde el plan no se cumplieron por causa de la corrupción y en gran medida por la desarticulación de las políticas a la realidad de los territorios. (mencionado por el DNP, 1991).

- El Salto Social denominado el periodo de 1994-1998 en el Plan Nacional de Desarrollo, en su eslogan Más y Mejores Empleos, se fomenta la política a la microempresas fomentando la inversión y la aprobación de proyectos para la formación empresarial. (mencionado por el DNP, 1996). En cuanto a la inversión en el sector rural mediante la reforma agraria llevado a cabo durante este periodo se buscó otorgar tierras a familias campesinas e indígenas como también la constitución de resguardos alcanzando el 14\% de cumplimiento en las metas formuladas para este sector se fortaleció el SINA y se lograron reforestar más de 11.500 hectáreas (DNP, 1996).

- Periodo complejo en términos de dialogo de paz - 1998-2002 - en cuanto a las estrategias era la de construir un país en paz. Centrándose en las mayores aspiraciones y necesidades con las que contaba la población colombiana a través de los conversatorios realizados en el Municipio del Caguan; donde se consideraba una reforma política para asegurar el retorno de la 
gobernabilidad del estado dentro del territorio nacional en torno a la modernización de la administración pública y la profundización de la descentralización; redefinición del papel estatal; reducción de la duplicidad de funciones, programas y proyectos, racionalización del gasto público; desarrollo del proceso de descentralización y adecuada y eficiente prestación de servicios y cumplimiento de funciones (DNP, 1998). De igual forma esta es una forma para retomar y consolidar la sostenibilidad del desarrollo para iniciar la construcción de la paz; puesto que esta es un arma poderosa; que genera efectos positivos en la reducción de la pobreza, ya que en este periodo se alcanzaba el $60 \%$ de la población colombiana en el nivel de pobreza.

En cuanto al tema ambiental se desarrolló la continuidad de la política ambiental nacional donde se fijó el agua como eje articulador de la política, estableciéndose así objetivos de conservación y restauración de áreas prioritarias en las ecorregiones estratégicas; dinamizando el desarrollo urbano - regional sostenible y construir a la sostenibilidad ambiental de los distintos sectores, se avanzó en el diseño e implementación del Sistema de Información para Colombia (SIAC). (DNP. 1998).

Dos periodos continuos visualizaron ante el electorado y a traves del Congreso de la República, la relección presidencial. Lo anterior es el proyecto en el tiempo determinantes; por ello, los periodos de 2012 a 2018 se intensificaron los periodos presidenciales por la reelección para darle continuidad a proyectos puntuales que fortalecerían el modelo económico desde la seguridad democrática en darle garantías al sector productivo en su desarrollo y fortalecer los proyectos extractivos dentro del modelo económico como las denominadas locomotoras representadas en los sectores energéticos para terminar en el denominado concepto de desarrollo sostenible a través de crecimiento verde como criterio para ingresar a la OCDE.

\section{Resultados y Discusión}

De los 1103 municipios, el 88\% son clasificados como territorios rurales muchos de ellos dispersos y aislados de la inversión estatal; el conflicto armado ha sido uno de los causantes del desplazamiento de poblaciones más alto llevado en Latinoamérica y del Caribe. Las herramientas de planificación y de gestión territorial conocidos como los planes de desarrollo y planes de ordenamiento; lo cual, a traves de ellos, se planifica la localización de proyectos y su futura inversión en lo ambiental, social, económico, fortalecimiento administrativo e institucional y la articulación territorial con la puesta en marcha de infraestructura vial primaria y terciaría a lo largo del territorio nacional, con la mira del desarrollo y crecimiento municipal.

La identificación de problemas y algunas fortalezas municipales están directamente relacionado con la propiedad y uso de la tierra en zonas de reserva ambiental, como de la disponibilidad de recursos naturales, desarrollo de actividad agropecuaria, áreas forestales y minera. Oferta para el desarrollo y crecimiento en el campo de infraestructura, bienes y servicios públicos, seguridad alimentaria. Todo ello, para enfrentar en el ordenamiento territorial y en la ejecución de planes de desarrollo municipal, articulados a la productividad rural, con la necesidad de articularlos al desarrollo y crecimiento con mayor gobernabilidad con instituciones fuertes que garanticen el cumplimiento de las inversiones y gastos públicos en beneficio de la colectividad y focalizada en el fortalecimiento de la participación de 
la sociedad civil a traves de consejos comunitarios y comités decisorios modelándose así espacialmente la participación de la mayoría de los actores y sectores en el territorio. El gobierno nacional a traves del plan Nacional de Desarrollo 2010 - 2014 propone la puesta en marcha de la Unidad Administrativa Especial para la Consolidación Territorial (UAECT). Como eje central en el enlace entre los departamentos y municipios y estos con la nación.

El siguiente paso, es el de áreas de concentración referente a territorios denominados de paz, nos ha llevado al reconocimiento e implementación de herramientas de gestión y de planificación territorial, las cuales, utilizadas de tal forma que se puedan articular entre municipios veredas, estas entre departamentos y a la ves con las directrices creadas por el Estado Colombiano como la Unidad Administrativa Especial para la Consolidación Territorial (UAECT - Sede Central la Ciudad de Bogotá D.C.); lo que obliga la articulación de políticas públicas enmarcadas en la ejecución de programas y proyectos nacionales, departamentales y municipales entre sí, además de recursos de financiación internacional. Finalmente, el siguiente paso, es el de articular los vínculos espaciales de las ciudades capitales de las regiones conformadas a través de la asociatividad departamental e integradas por las UPGT. Véase figura No 4. Espacialización del modelo espacial para la evaluación y gestión del territorio para la incorporación de las UPGT al pos-conflicto colombiano.

Lo anterior, dispone de una visión integral del desarrollo y crecimiento territorial, además de entender lo que ha sucedido en el pasado en términos ambientales, sociales y económicos, que administrativamente no se representó en un mejoramiento de calidad de vida de la población nacional durante los doce planes de desarrollo evaluados (1970 al 2018). Aun así, para el gobierno nacional el país ha crecido económicamente, además de consolidarse como la región más representativa dentro de los niveles democráticos y estabilidad económica en la región (Suramérica). Al final, que estaríamos discutiendo entre dos actores que por más de cincuenta años han mantenido su disputa hegemónica en el territorio sin comprenderse hasta hoy. El tema de conflicto interno y el crecimiento socioeconómico causan grandes dudas del modelo institucional hasta hoy vigente; el reto en tiempos de posconflicto es la posibilidad que los planes de desarrollo departamental y municipales integren los verdaderos postulados de cambio que se firmaron en la Habana (Cuba), y que atraves del modelo propuesto para la evaluación del proceso de paz, espacialmente se garantice la articulación del gobierno nacional con el resto del territorio a traves de los departamentos y de estos a los municipios.

\section{Estimación de la propuesta del Modelo}

La propuesta de modelo se escogió de acuerdo a los resultados del proceso de investigación y formulación de las Unidades de Planificación y de Gestión Territorial (UPGT), cuyas funciones garantizarán tanto en el presente como en el futuro el desarrollo institucional y su armonización de los distintos actores en la ejecución de programas y proyectos integrando distintas herramientas de planificación como son los POTs; POMCAS, PDN, PDD y PDM entre otros. Para ello, su armonización obedece a las distintas características geofísicas del territorio como administrativas en su organización política. Véase figura No 4. Espacialización del modelo espacial para la evaluación y gestión del territorio para la incorporación de las UPGT al posconflicto colombiano.

En la siguiente figura No 5, en color rojo, se puede verificarlas las condiciones de gestión institucional en algunos aspectos cuantitativos de capacidad institucional en que se encuentran los municipios colombianos referidos a: lo citado retomado por (Gutiérrez, 2010 pp 26 -27) ; precariedad 
institucional característica de las zonas de periferia a consecuencia de la implantación de las elites políticas localizadas en Bogotá y en otras grandes capitales, en la implantación del modelo de intermediación; lo cual, se compararon tres dimensiones de la capacidad institucional como organización: I. la provisión de justicia, II. La capacidad tributaria III. Y la gestión administrativa del municipio. Estas tres dan respuesta a las funciones del Estado que debe llevar a cabo a lo largo del territorio nacional.

Esto quiere decir, que la localización de departamentos y municipios (veredas) véase figura Espacialización del modelo espacial para la evaluación y gestión del territorio para la incorporación de las UPGT al pos-conflicto colombiano. Demuestra la importancia de fortalecer a la periferia con los cambios de institucionalidad y gestión territorial, dando énfasis en la consolidación de nuevos territorios con los nuevos actores que hoy tiene el denominado de sociedad civil, que tendrán la capacidad de demostrar el porqué de más de cinco décadas ejercieron presencia asumiendo la responsabilidad de Estado.

Figura No 4. Zonificación espacial de los municipios con características de capacidad Institucional Baja y Crítica.

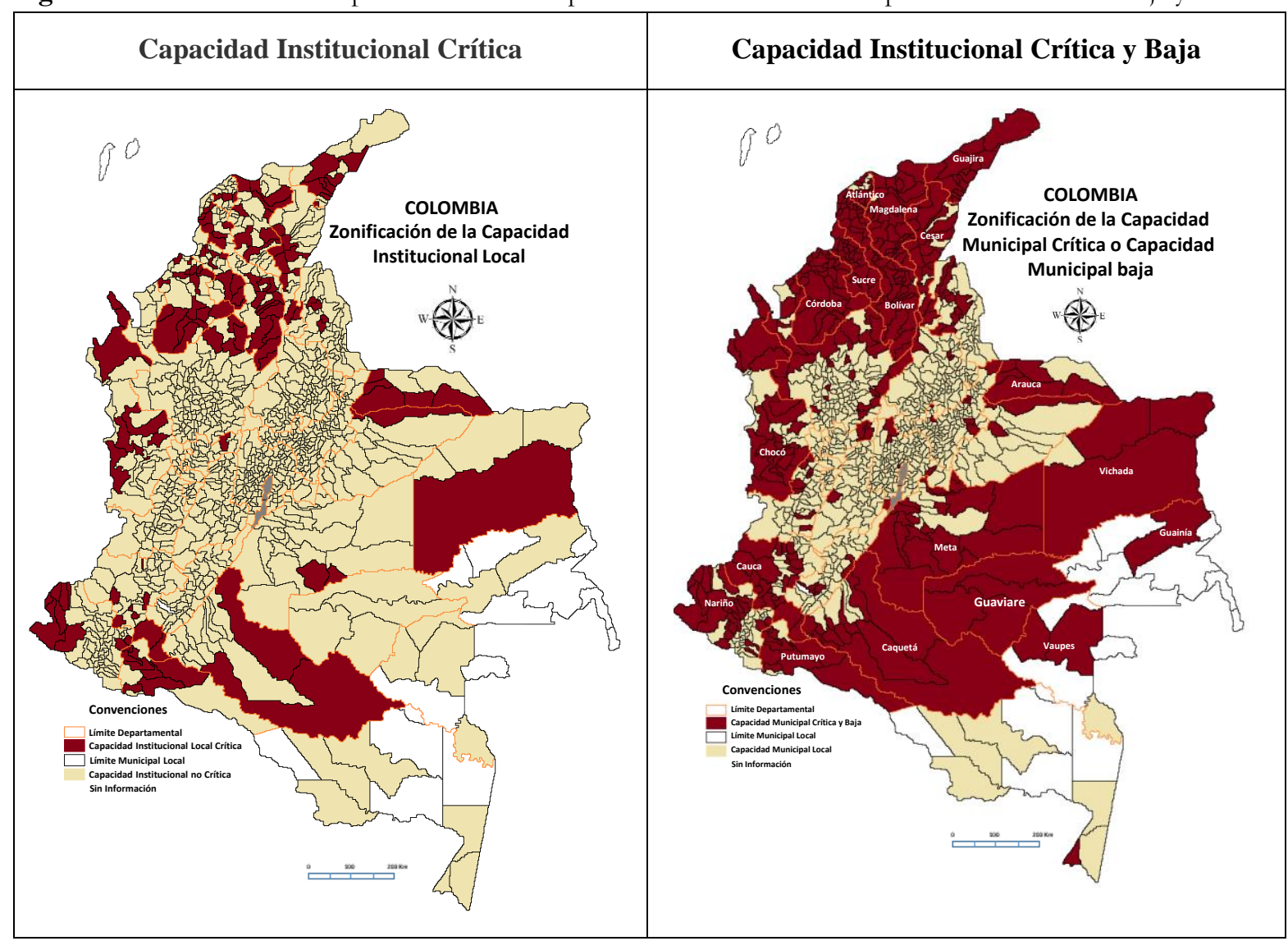

Fuente: Elaboración Arq. Ernesto Villegas Rodriguez, 
Figura No 5. Espacialización del modelo espacial para la evaluación y gestión del territorio para la incorporación de las UPGT al pos-conflicto colombiano.

\section{Zonas Veredales Transitorias de Normalización - ZVTN-}

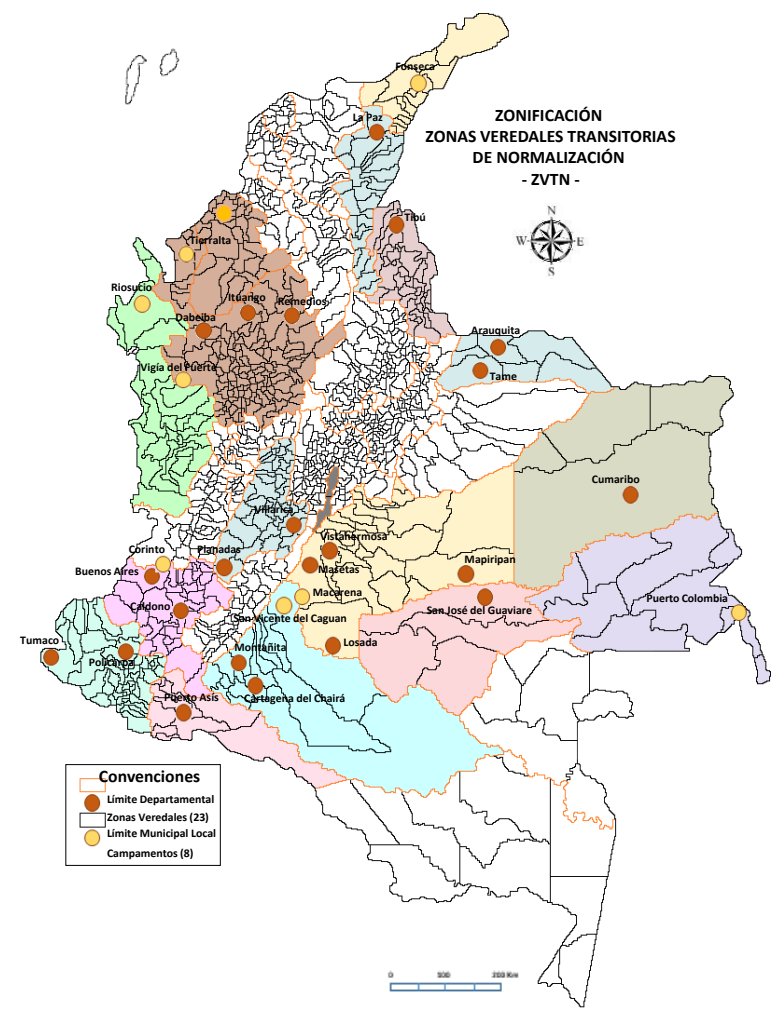

\section{UPGT en las Zonas Veredales Transitorias de Normalización - ZVTN-}

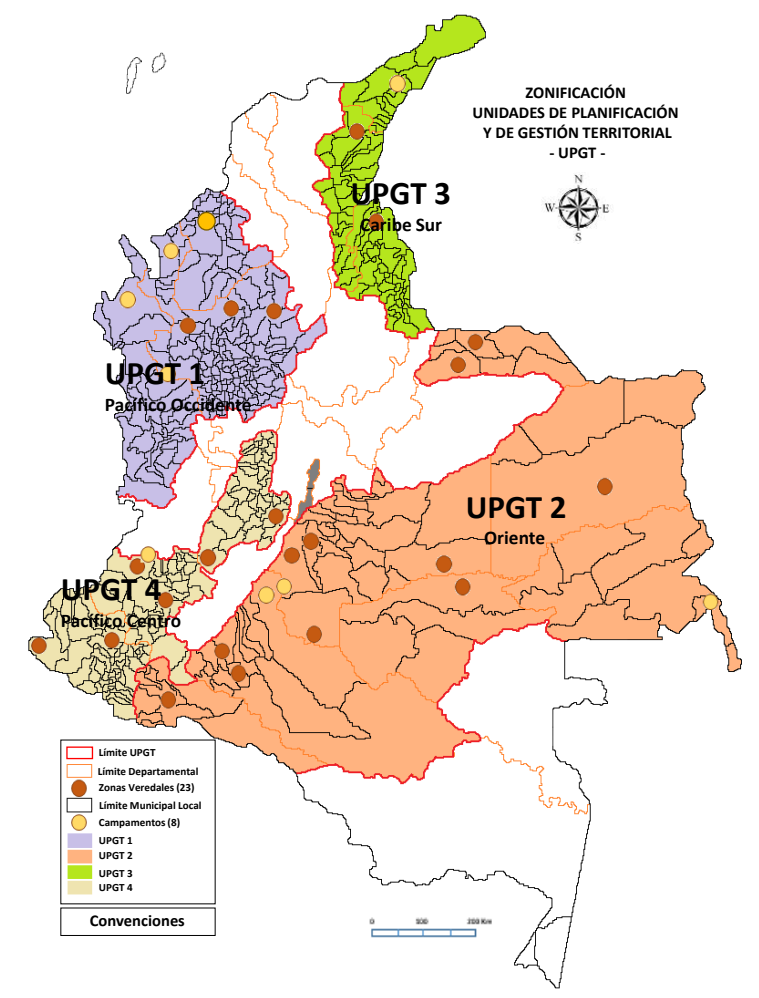

Fuente: Elaboración Arq. Ernesto Villegas Rodríguez.

El aporte de este artículo, es el resultado de un proceso de investigación que a lo largo de catedras de planificación y administración del desarrollo regional, se ha entendido la importancia de implementar el criterio de las Unidad de Planificación Territorial (UPGT); citado (Villegas Rodríguez 2015), en el libro Contexto de la planificación territorial, con el fin de consolidar el desarrollo económico, social, ambiental e institucional del país a traves de la armonización de políticas públicas (instrumentos de planificación) y sus herramientas de gestión (planes de desarrollo territorial - Planes de Ordenamiento Territorial POT, PEOT, PBOT) y Planes de Manejo y Ordenamiento de Cuencas Hidrográficas conocidos como los POMCAS y POMCH) entre otros.

La propuesta de Modelo Espacial, se consolida como se puede ver en la figura anterior en cuatro regiones articuladas desde las UPGT, además véase la figura Vínculos Espaciales, Unidades de Planificación y de Gestión Territorial UPGT. 
Figura No 6. Vínculos Espaciales, Unidades de Planificación y de Gestión Territorial UPGT

\section{Vínculos Espaciales Centro, Departamental, Municipal y Veredal}

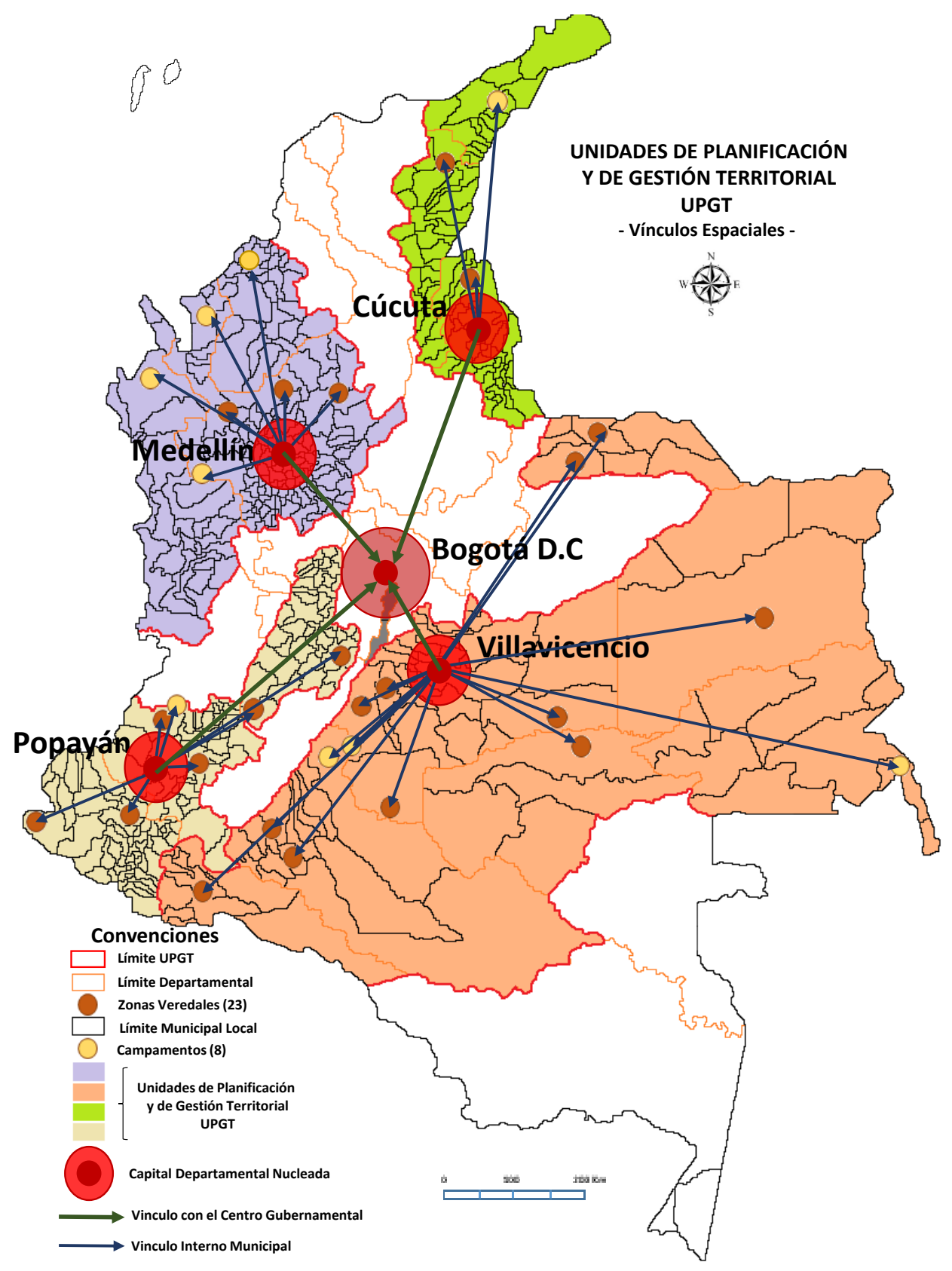

Fuente: Elaboración Arq. Ernesto Villegas Rodríguez

Las condiciones están dadas en el marco de la gestión institucional en Posconflicto, donde los innumerables recursos económicos y humanos para llevar a cabo el nuevo esquema territorial que será enmarcado en territorios galantes del desarrollo con equidad y un crecimiento sostenible y duradero. Que garantice la articulación de Programas y Proyectos articulados a los siguientes Planes: Planes de 
Desarrollo Nacionales, Planes de desarrollo Departamentales y la consolidación de una Segunda Generación de Planes de Desarrollo. Véase (Villegas 2014), Municipales Territoriales los cuales estarán bajo las características de nuevos territorios institucionalmente viables; verificados en términos de seguimiento y evaluación por las cuatro capitales de las regiones como: Villavicencio, Cúcuta, Popayán y Medellín; enmarcadas desde las decisiones del gobierno Nacional como lo establecido en la política Territorial de la Constitución Política de 1991. (Véase tabla No)

Tabla No 5. Unidades de Planificación y de Gestión Territorial UPGT Énfasis regional.

\begin{tabular}{|c|c|c|c|}
\hline Región & Departamentos & $\begin{array}{c}\text { Centro poblado } \\
\text { Galante en la armonización } \\
\text { regional }\end{array}$ & $\begin{array}{c}\text { Total } \\
\text { DPTOS }\end{array}$ \\
\hline 1. & $\begin{array}{l}\text { Unidad Especial de articulación } \\
\text { Nivel Nacional. }\end{array}$ & Ciudad de Bogotá D.C. & 1 \\
\hline $\begin{array}{ll}\text { 2. } & \text { UPGT } \\
& \text { Pacífico } \\
& \text { Occidente }\end{array}$ & Chocó, Antioquia y Córdoba. & Ciudad de Medellín & 3 \\
\hline $\begin{array}{ll}\text { 3. } & \text { UPGT } \\
& \text { Oriente }\end{array}$ & $\begin{array}{l}\text { Arauca, meta, Putumayo, Caquetá, } \\
\text { Vichada, Gaviare, Guainía. }\end{array}$ & Ciudad de Villavicencio & 7 \\
\hline $\begin{array}{l}\text { 4. UPGT } \\
\text { Caribe } \\
\text { Sur }\end{array}$ & Guajira, Cesar y Santander. & Ciudad de Cúcuta & 3 \\
\hline $\begin{array}{ll}\text { 5. } & \text { UPGT } \\
\text { Pacífico } \\
\text { Centro }\end{array}$ & Nariño, Cauca y Tolima. & Ciudad de Popayán & 3 \\
\hline
\end{tabular}

Fuente: Elaboración Arq. Ernesto Villegas Rodríguez.

\section{Políticas Orientadoras}

La construcción de la propuesta para el proceso de armonización para llevar acabo el Modelo espacial para la evaluación y gestión del territorio para la incorporación de las UPGT al pos-conflicto colombiano; se identificará desde las políticas orientadores promulgadas a lo largo de la última década, entre ellas

El Modelo se soportará en el siguiente marco orientador:

Participación: En lo posible, la propuesta se adelantará con la participación plural de representantes de los diferentes estamentos del territorio zonificado a través de las UPGT.

Flexibilidad: permitirá el empleo de distintos instrumentos de planificación como de las herramientas de gestión en el trabajo tanto individual (UPGT), como grupales (Interrelación de las UPGT) que aseguren los resultados a alcanzar desde la visión de las dimensio0nes ambiental, social, económica, administrativa.

Monitoreo y Seguimiento constante: El Monitoreo y Seguimiento al proceso de armonización, la planeación será permanente y contará con su propio sistema de evaluación y control, desarrollado entre los distintos actores y sectores involucrados. 
Acotación: se contará administrativamente con un plazo fijo y perentorio determinado por la Alta Dirección del Estado colombiano en asocio a con los integrantes de las UPGT, para su evaluación y seguimiento en el cumplimiento de las políticas.

\section{Estructura organizativa}

La propuesta de trabajo para el Modelo espacial para la evaluación y gestión del territorio para la incorporación de las UPGT al pos-conflicto colombiano se contará con las cuatro Unidades de Planificación y de Gestión Territorial y de Gestión Territorial identificadas con la Sigla UPGT, incluye dos tipos de estructura, de carácter complementario:

\section{La primera, una estructura organizativa encargada del diseño, impulso y coordinación de las diferentes fases y actividades relacionadas con la construcción del Plan}

Implica la identificación de los integrantes del equipo de expertos, sus responsabilidades, la planificación del tiempo de ejecución de tareas y la presentación de avances y resultados con relación al diseño de las UPGT.

A continuación, se presenta el Modelo administrativo.

El Comité Ejecutivo, es el responsable directo de la construcción del nuevo proceso institucional, según la propuesta del modelo espacial para la evaluación y gestión del territorio para la incorporación de las UPGT al pos-conflicto colombiano. Su función es impulsar y legitimar la elaboración y puesta en marcha del proceso de paz. Está conformado por las propias instancias del estado central delegadas por el presidente de la República para el fin de la paz; posteriormente lo conformaran los representantes de las capitales regionales; véase Figura No 6. Vínculos Espaciales, Unidades de Planificación y de Gestión Territorial UPGT. Donde para la Región 0ccidente lo representará la ciudad de Medellín (UPGT 1); Región Oriente la ciudad de Villavicencio (UPGT 2); Región Caribe Sur la ciudad de Cúcuta (UPGT 3) y la Región Pacífico Centro la ciudad de Popayán (UPGT 4). Con sus respectivos delegados escogidos por los gobernadores de los departamentos y alcaldes de los municipios integrantes de cada región.

La Secretaria técnica: es la instancia encargada del proceso administrativo de planificación, organización, gestión y sistematización del trabajo de la construcción del proceso de Paz; elaboración de los documentos y presentación de los resultados y avances al Comité ejecutivo. Estará a cargo de la Dirección de Planeación y Desarrollo Institucional y del Comité Técnico supervisado por el Departamento Nacional de Planeación DNP.

El Comte Técnico Asesor: Tiene la función de asistir como instancia asesora a la Secretaria Técnica en la generación de trabajos puntuales al proceso de paz para articular los distintos Planes de Desarrollo tanto departamentales como municipales desde una visión regional de los cuatros entidades administrativas conformadas.

Comisiones Técnicas: Equipos de trabajo que se conforman y actúan bajo la figura de mesas temáticas de trabajo, según las propias dinámicas del proceso, en sus etapas proyectadas posteriores a la dejación de armas y el retorno a la vida civil. 
Grafica No 2. Estructura administrativa para el Posconflicto

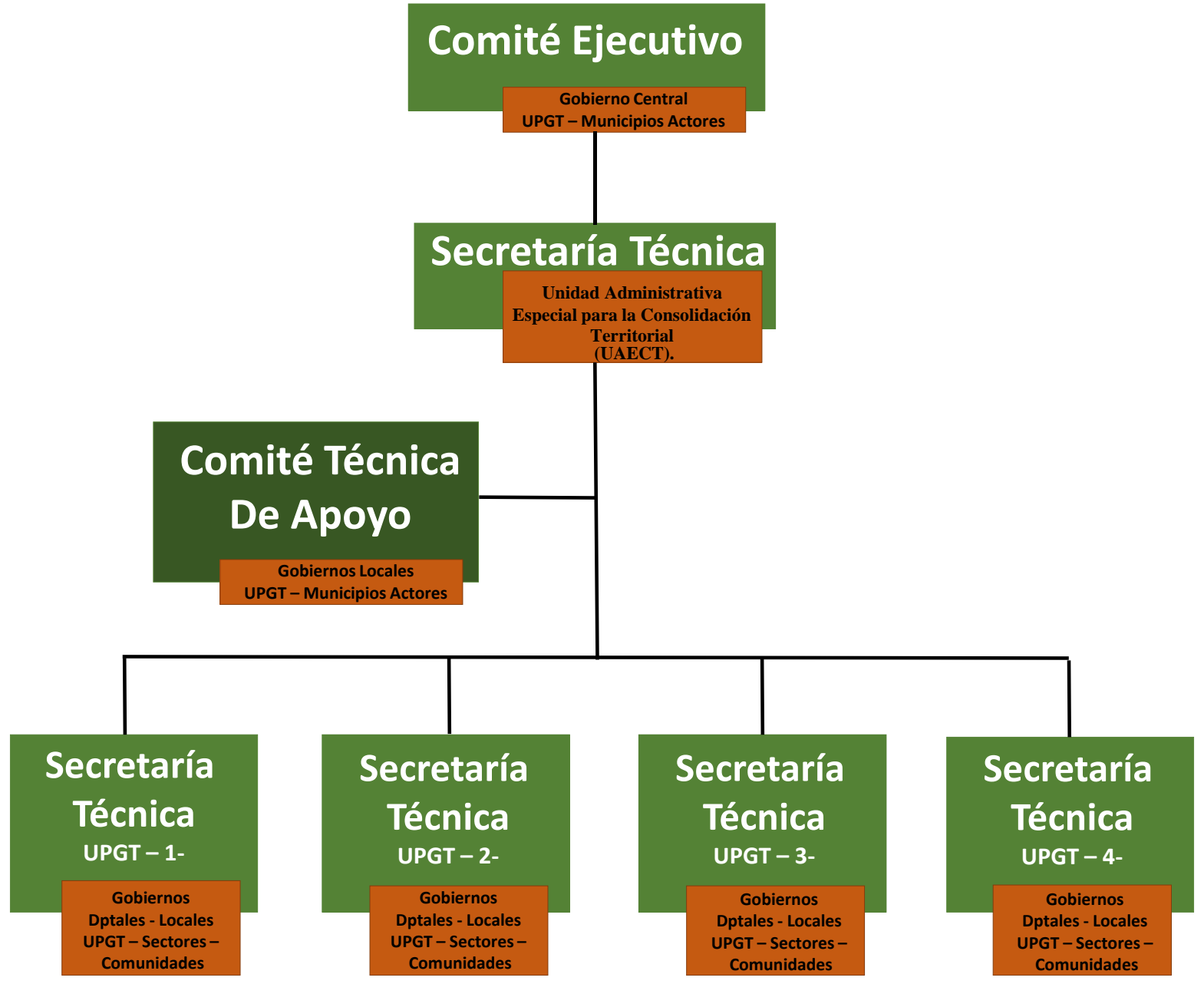

Fuente: Elaboración Arq. Ernesto Villegas Rodriguez.

\section{La segunda, una estructura organizativa de dirección y manejo (gobernanza y Gobernabilidad)}

Finalmente, el proceso de paz para una paz duradera se necesita darle continuidad a los procesos gubernamentales representados por los propios actores que han de conformar los nuevos territorios y democráticamente establecer desde el gobierno nacional las reglas claras en la ocupación de los nuevos territorios. Se Conforman tres órganos responsables: Primero el Órgano de aprobación de los distintos programas y proyectos de inversión en infraestructura que se implementarán en los tiempos programados para su puesta en marcha y posterior ejecución y seguimiento. Segundo el Órgano de Direccionamiento que define la vinculación o participación política de líderes y lideresas de la comunidad localizadas en cada una de las cuatro Regiones UPGT. Y Tercero el Órgano Ejecutivo, encargado de la administración y gestión conjunta de las cuatro (UPGT), con el centro del país (Ciudad de Bogotá D.C. Presidencia de la república) para asegurar la legitimidad, apropiación, internalización y corresponsabilidad en la implementación y ejecución de las Regiones UPGT. Las cuales deben contar con las siguientes características fundamentales: liderazgo, nivel de institucionalidad y administración 
de gestión territorial, capacidad analística y sentido de pertenencia con los territorios y con las instituciones que las conforman.

\section{Referencias Bibliográficas}

2014, E. V. (Volumen 13 Número 1 enero - junio de 2014). Revista de Tecnología Journal of Technology, ISSN 1692-1399 PP 139 - 142. Bogotá D.C. : Universidad El Bosque.

Aponte, C. R. ((2015).). Análisis de datos espaciales del Índice.

Aponte, C. R. (2015). Análisis de datos espaciales del Índice de necesidades Básicas Insatisfechas en la Rwegión Andina. . Bogotá D.C. : Perspectivas Geográficas.

Aponte, C., Romero, E. \& Santa, L. F. (2015). Análisis de datos espaciales del Índice. (s.f.).

C., L. (2016). jAdios a las Farci ¿Y ahora que? Bogotá D.C. : Debate.

Cesar Rodríguez garavito, D. R. (Enero 2017). La Paz. Ambiental, Retos y propuestas para el posacuerdo . Bogotá D.C. : Justicia Antropos Ltda.

Colombia, C. d. (2000). Ley 617 Categorización de las Entidades Territoriales (presupuestos) . Bogota. D.C. : Diario Oficial No 44.188 de 9 de octubre de 2000.

Colombia, C. d. (2017). Ley Organica de Ordenamiento Territorial (Ley 1454 de 2011). Bogotá D.C. : Imprenta Nacional de Colombia .

Colombia, C. N. (2000). Ley 614 de 2000 por la cual se adicioan la ley 388 de 2997 y se crean los Comites de Integración Territorialpara la adopción de los planes de ordenamiento territorial . Bogota.D.C.: Diario oficial 44.168 del 20 de septiembre de 2000 .

Colombia, C. N. (Abril 24 de 2013). Ley 1523 de 2013 Por la cual se adopta la política nacional de gestión de desastres y se establece el Sistema Nacional de Gestión del Riesgo de Desastres. Bogotá D.C. : Diario Oficial 48411 de abril 24 de 2012.

Colombia, C. N. (julio 15 de 1994). Ley 152 de 1994, por la cual se establece la Ley Organica del Plan de Desarrollo. Bogotá D.C. : Diario oficial No 41.450.

Colombia, C. N. (Junio 9 de 2015). Ley 1753 de 2015 Por la cual se expide el Plan Nacional de Desarrollo 2014-2018 "todos por un nuevo país. Bogotá D.C.: DNP Departamento Nacional de Planeación.

Colombia, E. C. (1997). Ley 388 de 1997, por la cual se modifica la ley 9 a de 1989 y la ley 3 a de 1991 y se ductan otras disposiciones. Bogotá D.C. : Congreso de la República de Colombia imprenta Nacional .

Diplomacia municipaly otras iniciativas d elos gobiernos locales para construir la pa\%: (Noviembre de 2008). Ideas para construir la paz. Cooperativa municipal para la paz .

Ernesto, V. R. (noviembre 2015). Contexto de la planificación territorial. Hacia la aplicación de instrumentos de gestión Urbano Rural,. Bogiotá.D.C. : Ediciones Universidad de América.

Gilberto Cámara, M. S. (2006). Analise Espacial de Areas. Brasil .

Ingrid Acevedo Bohorquez, E. V. (2008). Algunos conceptos de la Econometria Espacialy el Analisis expolratorio de datos espaciales. Medellín : Ecos de econompia .

Luis Armando Galvis, A. M. (No. 120, (2010). ). Persistencia de las desigualdades regionales en Colombia: Un análisis espacial. Centro de Estudios Económicos Regionales (CEER). Bogotá D.C.: Banco de la República. Documentos de trabajo sobre economía regional Espacial. . 
Mauricio Garcia Villegas, N. T. (Noviembre de 2016). Los Territorios de la Paz, La construcción del Estado Local en Colombia. Bogotá D.C. : Ediciones Antropos Ltda.

Ministerio de Vivienda Ordenamiento Territorial y Medio Ambiente, D. N. (Diciembre de 2013). ISBN: 978-9974-8259-8-7 Diciembre de 2013. Bogotá: Ministerio de Vivienda Ordenamiento Territorial y Medio Ambiente.

Rodríguez, E. V. (enero - junio de 2014). Volumen 13 Número 1,. Revista de Tecnología Journal of Technology ISSN 1692-1399, 139 - 142.

Rozas, J. C. (2006). Unidad de Recursos Forestales, CITA . Galicia Pontevedra : Gobierno de Aragón Zaragoza Départamento de Ecología CIFA de Lourizán Pontevedra .

Sostenible, M. d. (2012). Decreto Número 1640 de 2 de agoto de 2012, por el cual se reglamentan los instrumentos para la planificación, ordenación y manejo de las cuencas hidrograficas y acuiferos. Bogotá D.C. : Ministerio de Ambiente y Desarrollo Sostenible. 